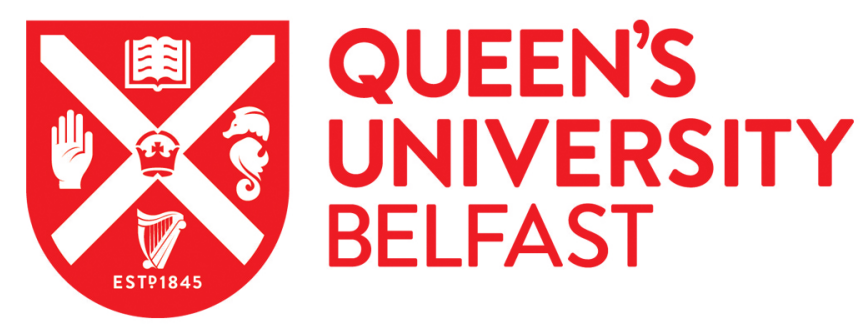

\title{
The experiences of family carers in the delivery of invasive clinical interventions for young people with complex intellectual disabilities Policy disconnect or policy opportunity?
}

Brown, M., Hoyle, L., \& Karatzias, T. (2016). The experiences of family carers in the delivery of invasive clinical interventions for young people with complex intellectual disabilities Policy disconnect or policy opportunity? Journal of Clinical Nursing, 25(3-4), 534-542. https://doi.org/10.1111/jocn.13090

Published in:

Journal of Clinical Nursing

Document Version:

Peer reviewed version

Queen's University Belfast - Research Portal:

Link to publication record in Queen's University Belfast Research Portal

Publisher rights

(c) 2016 John Wiley \& Sons Ltd.

This work is made available online in accordance with the publisher's policies. Please refer to any applicable terms of use of the publisher.

\section{General rights}

Copyright for the publications made accessible via the Queen's University Belfast Research Portal is retained by the author(s) and / or other copyright owners and it is a condition of accessing these publications that users recognise and abide by the legal requirements associated with these rights.

\section{Take down policy}

The Research Portal is Queen's institutional repository that provides access to Queen's research output. Every effort has been made to ensure that content in the Research Portal does not infringe any person's rights, or applicable UK laws. If you discover content in the

Research Portal that you believe breaches copyright or violates any law, please contact openaccess@qub.ac.uk. 


\section{Journal of Clinical Nursing}

The experiences of family carers in the delivery of Invasive Clinical Interventions for young people with complex intellectual disabilities: Policy disconnect or policy opportunity?

\section{Professor Michael BROWN}

$\mathrm{PhD}, \mathrm{RGN}, \mathrm{RNLD}$, Professor of Health and Social Care Research, Faculty of Health, Life \& Social Sciences, Edinburgh Napier University, Sighthill Campus, Sighthill Court, Edinburgh, EH12 4BU, Scotland, UK and Nurse Consultant, NHS Lothian. m.brown@ napier.ac.uk

\section{Dr Louise HOYLE}

PhD, BNurs (Hons), RN

Lecturer of Nursing, Faculty of Health, Life \& Social Sciences, Edinburgh Napier University, Sighthill Campus, Sighthill Court, Edinburgh, EH12 4BU, Scotland, UK

Professor Thanos KARATZIAS

$\mathrm{PhD}, \mathrm{MSc}, \mathrm{BSc}$

Professor of Mental Health, Faculty of Health, Life \& Social Sciences, Edinburgh Napier University, Sighthill Campus, Sighthill Court, Edinburgh, EH12 4BU, Scotland, UK and Honorary Clinical Psychologist, NHS Lothian

Acknowledgments: Jane Gray, Chief Executive \& Fiona Katz, HR Director, ARK Housing and team for their assistance in undertaking this study.

Funding: ARK Housing Association funded this study 


\section{Abstract}

Aim

To explore family carers experiences of invasive clinical interventions within the community.

Background

People with learning disabilities are living longer with a range of complex needs that may require invasive clinical interventions. There will be a growing demand for the delivery of these interventions within the community.

Design

An interpretivist qualitative design.

Methods

Semi-structured interviews were carried out with 10 family carers of children with complex care needs requiring invasive clinical interventions.

Findings

There are barriers identified in relation to the delivery of invasive clinical interventions in the home setting by social care support workers. These include a reluctance to carry out an invasive clinical intervention both for family carers and staff, anxiety, a lack of knowledge and training and difficulties in recruiting appropriate staff.

\section{Conclusions}

There needs to be a shift to implement policy on the needs of people who will increasingly be cared for in the community and requiring invasive clinical interventions.

Key words: Nursing, nurses, intellectual disabilities, invasive clinical procedures, co-production, community care, health needs, support workers, education, policy implementation 


\section{Why is this research needed?}

- The population of children with intellectual disabilities and complex physical health needs is increasing and living into older age

- Children with intellectual disabilities and complex physical health needs require access to a range of invasive clinical interventions to maintain their health and enable social inclusion

- There has been a shift to community care away from institutional models of care, with a need to prepare non health professionals to delivery invasive clinical interventions

\section{What are the key findings?}

- Parents are the main providers of invasive clinical interventions in childhood and have a role to play in educating others in the needs of their child

- There is an increasing focus on the social care workforce to deliver invasive clinical interventions to children health complex health needs in the community

- There is a need to plan for the needs of this population as they age and require invasive clinical interventions in the community

\section{How should the findings be used to influence policy/practice/research/education?}

- There is a need to strategically develop and implement policies to enable the wide delivery of invasive clinical interventions

- There is a need for Registered Nurses to develop their knowledge and skills related to the wider delivery of invasive clinical interventions for adults with intellectual disabilities

- There is a need for Registered Nurses to share skills related to invasive clinical interventions with social care support workers to meet future care needs 


\section{Introduction}

The global population is aging; this includes children and adults with intellectual disabilities and those with other care needs, such as dementia (WHO 2011). Due to increasing longevity, more people with intellectual disabilities are living into older age with a range of complex health needs that render some technologically dependent and in need of regular on-going health interventions necessary to maintain their health and wellbeing (Glendinning et al. 2001, MacKay et al. 2010,). Many people with intellectual disabilities increasingly have their care needs met within the community and as they live longer and with more complex needs, there will be a growing demand for health and social care interventions, including invasive clinical interventions (Bardsley et al. 2011). This has significant implications for the way in which care services are and will be provided in the future (Emerson \& Baines 2010, WHO 2011).

\section{Background}

\section{Invasive Clinical Interventions}

Invasive Clinical Interventions (ICIs) are interventions that are carried out by healthcare providers in order to assess, maintain, treat or improve health. ICIs can include both invasive and non-invasive procedures (Bulechek et al. 2008)and can be therapeutic or diagnostic (METeOR 2005). Henderson \& Knapp (2005) refer to the measures taken to resuscitate a patient as an “invasive intervention", and 'The Keys to Life' (Scottish Government 2013:102-3) state that invasive interventions are 'not only life enhancing but lifesaving'. Gerrard et al. (2010) highlight that there is no agreed objective definition of a health care intervention as invasive, either nationally or internationally, and the terms procedure and intervention are often used interchangeably. Having reviewed the literature and in the absence of an agreed definition, the 
researchers developed and offer the following: 'An ICI is when a foreign object invades the body. This includes the puncturing of the skin, administration of non-oral medication, insertion of medical devices, care following medical procedures (e.g. stoma care, catheter care). ICIs require close contact between provider and recipient and will be personal in nature'. For the purpose of this study the term invasive clinical intervention will be used.

In 2008 the Royal College of Nursing (RCN) in the United Kingdom published details of the range of ICIs that could be delegated to non-registered practitioners involved in the care of children and training was required. The RCN publication details that preparation should occur at two levels: 1. General education about complex needs and 2. Education about a specific individual and the interventions or care that a person requires ( $R C N$ 2012: 5). There are further specific key elements which need to be incorporated into a program, set out in table 1 .

Insert table one about here 
There is no defined equivalent set of ICIs for adults that may be delegated to non-registered health practitioners. While the RCN publication relates to children there could be relevance to carers of adults undertaking ICIs. This raises a question of what happens when children reach adulthood and move into adult care and who is competent to safely and effectively deliver ICIs. In a recent systematic review of the literature Hithersay et al. (2014) concluded that carers can successfully deliver screening procedures, health promotion interventions and interventions to improve coping skills, pain management and cognitive functioning. However, no previous research has been found by the researchers on family carers experiences of ICIs.

\title{
The Study
}

\begin{abstract}
Aims
The aim of the project was to explore the family carers experiences of clinical interventions and their views of future service needs.

The study questions were:

1. What are the experiences of family carers in relation to the delivery of ICIs?

2. What preparation and support have family carers had in relation to ICIs?

3. How do family carers view the future of their family member requiring ICIs?

4. What are the barriers and solutions to enable the delivery of ICIs?
\end{abstract}

\section{Design}

This study is a qualitative interpretivist study (Denzin \& Lincoln 2000; Crotty 2005). 


\section{Participants}

Purposive sampling was used to recruit participants. Participants were selected because of their knowledge and experience as carers of children and young people with complex care needs who require invasive clinical interventions. Participants were accessed through local and national voluntary organisations and charities. A total of $n=10$, face-to-face semi structured interviews ( $n$ =9) and telephone interviews ( $\mathrm{n}=1)$ were conducted between October 2013 and February 2014 with parents of children with complex needs. Individuals who wished to participate were invited to contact the research team for more information. Contact was made with 19 families who were interested in participating in the study and met inclusion criteria. Ten $(n=10)$ were finally recruited; the others did not due to a variety of reasons such as not responding to the participation requests after initial contact or their child becoming suddenly unwell. The majority of interviews were undertaken with the mother of the child $(n=9)$, however, for one interview both parents were present.

\section{Data Collection}

A semi-structured interview schedule was developed focusing on the definition of ICIs, the range of ICIs required, the range of practitioners involved, education and preparation to deliver ICIs, the provider of the preparation, the assessment of knowledge and skills, ongoing education and support, the role of direct payments in enabling care and the provision of ICIs in the future, relinquishing care, the knowledge and skills required by staff to deliver ICIs, family involvement in assessing competence and barriers and solutions to enable ICI delivery. Interviews took approximately one hour. 


\section{Ethical Considerations}

Ethical approval was obtained from the University Research Ethics and Governance Committee.

\section{Data Analysis}

QSR Nvivo (Version 10) was used as a data management tool for the study. Thematic analysis was employed for the analysis of the data. This type of analysis allows the identification, analysis and reporting of patterns (themes) within data (Strauss \& Corbin 1998; Braun \& Clarke 2006). Field notes were made at the time of interviews and highlighted any themes that appeared to be of interest to the researcher at the time of interview. Once fieldwork had been completed, a set of thematic categories (cf. Ritchie et al. 2008) were developed. This involved the reading and rereading through the data set by set and identifying re-occurring themes. The interviews were transcribed verbatim and analysed individually and collectively by the research team for consistency and agree the final themes, with Figure 1 showing the thematic map developed. Insert Figure one about here

\section{Validity, reliability \& rigor}

The interpretative approach taken in this research does not seek to claim generalizability; rather it is exploratory in nature and aims to offer insight into the phenomena being studied. The purpose of qualitative research is to focus on the phenomenon, with repeatability and reliability of less importance (Parahoo 1997). QSR Nvivo was used as a data management tool and provides an audit trail and this helped to ensure reliability as it enabled a systematic approach to be taken with data analysis (Bazeley 2008). 


\section{Results}

\section{The child}

Participants were recruited from various areas across Scotland. The age of children ranged from two to sixteen. There was a variety of diagnoses including genetic conditions, such as Down's syndrome and Edwards's syndrome, and others including quadriplegic athetoid cerebral palsy, microcephaly and profound and multiple learning disability. A range of invasive clinical interventions were being undertaken. The most common intervention was gastrostomy. Other interventions included the delivery of oxygen, suctioning - nasal and oral, delivery of nebulisers, tracheostomy care and nasogastric tube feeding. High levels of personal care and manual handling were reported for all children.

During the interviews when talking about the delivery of the ICI, a range of people and professional groups were involved in the child's care, set out in Table 2. With regards to family and friends, some participants indicated that it might not be appropriate for other family members, such as grandparents, to be involved in delivering ICIs or that family members or friends were not comfortable undertaking the role.

Insert Table two about here

\section{ICI definition}

All interviewees were asked to comment on the definition developed by the research team for an ICI. They were asked if this definition resonated with all participants, with some stating that it 
was "a pretty fair summary" (Parent Interview 1) and accurate. One went on to suggest that some ICIs could be viewed as more invasive than others, such as caring for a tracheostomy compared to nutrition via a gastrostomy. Therefore in the absence of a universally recognised definition, the researchers offer the one set out above.

\section{Barriers and solutions to ICIs}

The participants highlighted that one of the barriers was their reluctance to carry out some procedures. For some, there was increased anxiety and adverseness in undertaking some tasks such as changing a gastrostomy tube:

...the one thing we have not been trained in, we've resisted is if the button comes out obviously to be able to replace it and I can do many things for my son but the thought of doing that and getting it wrong just terrified me, so that's the one thing we would take him to hospital to get done (Parent Interview 3)

Some participants stated that staff could be reluctant to carry out an intervention: "we often find nurses are not very keen on suctioning" (Parent interview 3) and so this could create difficulties for the child's care and for parents. It was considered that a lack of knowledge or understanding could lead to anxiety and fear for the individual expected to carry out the intervention and could cause much concern for parents: "there has been instances that we wouldn't leave him with certain people 'cause they're not quite confident enough or trained as well" (Parent Interview 4). 
A barrier identified related to staff attitudes with participants highlighting that if the attitude was not appropriate or if they had concerns, they would not let the individual undertake a clinical intervention or be left alone with their child.

...it couldn't just be anybody; it'd have to be somebody I could trust, somebody who has medical background that knows enough about what to do. I'm quite fussy with that cause, I mean, I couldn't just leave (child) with anybody, I'd have to make sure they knew enough (parent interview 10)

Some stated that they could not recruit appropriate staff to undertake the work in the first place. This might have been due to not finding someone willing to undertake the role or due to organisations being short staffed.

\section{Education of parents}

Participants described their preparation to deliver an ICI, and how they were shown the procedure by a member of staff: "so a nurse in the hospital taught me" (parent interview 10), who also described the procedure and then they were supervised carrying out the ICI in the hospital. In one case a participant described the use of training dummies before undertaking the procedure on their child. With regards to the assessment of their knowledge and skills, it was reported by some parents, that they would not be allowed home from hospital with their child until staff were satisfied they could manage:

...It'd be fair to day we generally get released from (the hospital), so they're, you know, not really prepared to release us unless they're happy and ultimately we're happy that we've been trained (parent interview 4) 
However, a couple of parents were of the view that they were not adequately prepared to carry out ICIs at home: "I didn't feel well trained when I left hospital as all. I was all fingers and thumbs and pretty nervous" (parent interview 8).

The participants were asked about on-going education, with the majority reporting that their knowledge and skills had never been reassessed and they had not been offered any form of educational update. Some suggested that if they needed further support or training, they would just ask. Others would like updates, yet felt that it should be the responsibility of the health and social care support workers to offer them: "I kind of think that maybe that (ongoing training)should be offered to parents actually, is that they should approach you" (Parent interview 4).

\section{Education of practitioners}

Participants were asked about the training of staff who provide ICIs for their child. With regards to school, none of the parents had given the training of staff much consideration, and assumed that the staff would be trained appropriately by the school or organisation: "I would expect them to have had the training...so as far as I'm concerned they've had the training that they need" (Parent interview 2). This was slightly different to parent's views regarding home support staff where they had more involvement in the education of support staff and highlighted that staff need to understand the importance of delivering an ICI correctly:

... and likewise with the feeding, especially with NHS feeding, they need to understand that if they don't pass that tube correctly and they don't test that it's in the right place then that 
is bad, bad news. So I think to understand the consequences, it is important the people to appreciate (parent interview 3).

It was reported that having theory, practice and supervision were all important components of training and that it would not necessarily have to be a registered nurse delivering the ICI as long as an individual is adequately trained.. Some participants were of the view that in addition to the general training, the member of staff should also be trained for the specific child, for example:

...I think the important thing is that they have child specific knowledge as well as a general theoretical background of how to carry out the skill they actually need to be, I suppose, trained to work with that child because every child's going to have, well obviously, a unique kind of tolerance for different procedures (Parent interview 9)

Other participants commented that it would be useful for staff to have formal recognition by way of signoff and documentation to show they have been trained and are competent in the ICI:

...I think it is always good to have something on paper in case there's any come back, you know, something just to say that they've been signed off. I know that even, I've just changed (child) button for the first time. Supervised by one of the community nurses, and that all had to be signed off, so I'd rather it was documented (parent Interview 7).

\section{Parents role in educating practitioners}

Participants described their involvement in the preparation of staff caring for their child and they wanted to be involved in their education of staff to ensure the best care for their child: 
...I mean a nurse for instance would train somebody to suction, they might not have dealt with (child), whereas we deal with (child) all the time so we can give them all the wee hints and times about if you do this and if you don't do that and this is the best way to get the best suction, cause we know him better than anyone else, so I think it would be almost a bit silly to train staff without our input as well (Parent interview 1).

Some participants highlighted the need to supervise staff to independently undertake the interventions and some reported having to train their home care staff:

...I just witnessed the care staff doing what was required and after telling them how it was done and what to do and things, I then witnessed then doing it and then I was quite happy enough to carry on (parent interview 9).

...it's very straightforward but I had to go through it [training] with every care worker than came along I had to do it with everybody (parent interview 4)

\section{The future}

When asked about the future several of the participants indicated that they had not really thought about the future and for those that had, there was concern about the lack of suitable services and available support. Some parents spoke about keeping their child at home, others about the need for there to be somewhere to support their child when older:

...Well I would love it if he was able to be supported in a home kind of setting with live in care. I would think that would be the best possible scenario for him (parent interview 9). 
There was much anxiety raised about the provision of services as a child moves into adult services:

...We are worried about the future and what it'll mean and from what I can hear from other people, it is once a child moves into adult services you can get nothing and for our point of view that would mean that we both would have to pack in work and that has obviously significant consequences (parent interview 3).

Parents highlighted that they would like some service provision as the child moves into adults services; particularly important for families who wished for their child to remain living with them: "I would like there to be some sort of provision, perhaps a day service he can go to and that he can enjoy" (parent interview 3), "well he'll go to some sort of day centre I suppose, replacement of school" (parent interview 4).

\section{Discussion}

The population of children with intellectual disabilities living into adulthood is increasing, with many presenting with life-long conditions and is a phenomenon that will continue that will continue (Maulix et al. 2011, Oeseburg et al. 2011). As a consequence more people with intellectual disabilities will require invasive clinical interventions than have historically been delivered in social care settings (Elias \& Murphy 2012). To enable the delivery of person centred care at home, there will be an increasing demand for families and social care workers to deliver ICIs and for health practitioners, such as registered nurses, to prepare them. There are therefore important issues arising from this study that need to be considered in terms of the role of registered nurses preparing and supporting parents and social care support workers to undertake ICIs (Department of Health 2013). 
Parents wish to continue to care for their intellectually disabled family member as they age and move into adulthood and as a consequence of the disability; many continue to stay in the family home, cared for by their parents, long after siblings have moved on (Seltzer et al. 2011). Parents are therefore key to maintaining people with intellectual disabilities at home and to ensure that this is a reality there are potential barriers that need to be considered. A potential barrier relates to the reluctance of parents to undertake ICIs; this may be the case for some social care support workers too. Other issues that need to be considered and that are of importance to families is the attitude of support staff providing care for their family member within the home setting. The recruitment and retention of staff with the right attitudes and values needs to be addressed and there are therefore practice development and workforce issues that need to be considered and planned for now and in the future (Bigby et al. 2014). Without willing and appropriately prepared support workers, it will not be possible to deliver ICIs safely and effectively in the home setting. Ensuring that the social care workforce of the future have the education, preparation and supervision once trained to deliver ICIs is an issue that needs to be planned for in partnership with registered nurses who will be have a lead role in ensuring that they are competent and remain so (Wark et al. 2014).

The health needs of children with intellectual disabilities are not static and change over time and therefore reassessment is required to ensure that package of care are fit for purpose and that parents and staff providing ICIs and care have the knowledge and skills required (Boyle et al. 2011). With regards to education, parents reported that when their child was first in hospital they received good training and guidance, highlighting that both theory and practice were important in 
training them about the ICIs they would be required to deliver. However, there appears to be a lack of on-going education, skills refreshers and training updates, vital to ensure their knowledge and skills remain up-to-date (Wark et al. 2014). Assumptions were made by parents that school staff would have the skills and be trained and therefore they had little involvement in preparation. This however was not the case for home support staff and parents have a key role in their education and supervision. While this is understandable, it is a cause for concern if they have not received regular updates and refreshes to ensure their own practice is safe and up-todate before they skill share with support workers. Robust education, preparation and supervision for parents is therefore a key issue as some feel anxious about their abilities to undertake ICI and given the increasing population and demand in the future, this is a strategic issue that needs to be planned for. At present it appears that ICI education for parents and social care staff is patchy and opportunistic with no clear programme or means of assessing and evidencing competence. The absence of a planned and coordinated strategic approach to education, preparation and supervision offers the opportunity to offer accreditation for parents to delivery ICIs (Agranoff 2013).

While parents acknowledged the future and the transition process from child to adult care services, it was apparent that some had not given it much thought. However, for those that had or were already starting the transition process there were concerns about the availability of suitable service provision (Betz 2004, Kennedy \& Sawyers 2008). This therefore points to the need for transition planning to ensure that an up-to-date assessment of need and care plan that incorporates ICIs and the education of parents and support workers is clearly set out (American Academy of Pediatrics 2011). The role of Registered Nurses in the assessment, design, delivery, 
evaluation of education programmes and the decision whether to delegate ICIs is paramount to safe care. As registrants, nurses retain accountability for their actions, including safe delegation. It is therefore important that all Registered Nurses involved in the process fully understand the implications of skill sharing and delegation and their on-going role and responsibilities when delegating (Royal College of Nursing 2006, Standing \& Anthony 2008, Royal College of Nursing 2012, Hasson et al. 2013).

Part of the package of care for people with intellectual disabilities requiring ICIs is respite breaks. This adds another dimension to the delivery of ICIs as respite care workers will also need to be included in the education, preparation and supervision. At some point in the life of their family member, parents may opt to or need to relinquishing care and planning for this needs to be undertaken to ensure that care providers are identified, support workers recruited and prepared to safely deliver ICIs (Nankervis 2012). As the more people with intellectual disabilities require ICIs, there may be increasing demand for packages of care within and out with the family home setting. As a consequence there are wider workforce and resource needs need to be put in place now for the future (Agranoff 2013).

Strategically there is a need to develop new models of care and education to ensure that the needs of young people with intellectual disabilities who require ICIs receive them as they progress into adulthood. Workforce planning and development across health, social care and care providers needs to be established and coordinated to ensure that there is a knowledgeable and skilled workforce for the future (Buchan \& Seccombe 2011). Parents are key partners in their family members care and their development needs must be identified and met. As the role 
of health and social care services evolves to have more of a focus on the delivery of ICIs, it is important to ensure that their education and preparation reflects future needs (Department of Health 2013).

\section{Conclusion}

There has been a significant shift in the care of people with intellectual disabilities from institution to community home-based care and while this is welcomed there appears to be an emerging policy disconnect due to the absence of a focus of the needs of this population who require ICIs now and in the future. There is therefore a window of opportunity that needs to be grasped to ensure there is a reorientation of care services to ensure they have the capacity and infrastructure to meet future needs. Strategic vision, investment and development are required to enable the delivery of safe person centred home based care with families and patients at the heart. No literature related to education, preparation and supervision of social care support workers on the delivery of ICIs was identified in relation to adults with intellectual disabilities. There is therefore a need for strategic developments to take place and for further research into the opportunities and challenges faced by people with intellectual disabilities, their families, social care services and health practitioners in this area as the current evidence-base is underdeveloped and requires attention.

Funding: ARK Housing Association funded this study 


\section{References}

Agranoff R. (2013) The transforming of public sector intellectual/development disabilities Programming. Public Administration Review, 73 (11), S127-S138.

American Academy of Pediatrics (2011) Clinical report-Supporting the health care transition from adolescence to adulthood in the medical home. Pediatrics, 128 (1), 182-200.

Bardsley M., Billings J., Dixon J., Georghiou T., Lewis G.H. \& Steventon, A. (2011) Predicting who will use intensive social care: case finding tools based on linked health and social care data. Age and Ageing, 40, 265-270.

Bazeley P. (2008) Qualitative Data Analysis with NVivo, 2nd edn. Sage, London.

Betz C. (2004) Transition of adolescents with special health care needs: Review and analysis of the literature. Issues in Comprehensive Pediatric Nursing, 27, 179-241.

Bigby C., Know M., Beadle-Brown J. \& Celement T. (2014)'We just call them people': Positive regard as a dimension of culture in group homes for People with severe intellectual disability. Journal of Applied Research in Intellectual Disabilities. DOI: 10.1111/jar.12128

Boyle C., Boulet S., Schieve L., Cohen R., Blumberg S., Yeargin-Allsopp M., Visser S. \& Kogan M. (2011) Trends in the prevalence of developmental disabilities in US children, 19972008. Pediatrics, 127 (6), 1034-1042.

Braun V. \& Clarke V. (2006) Using thematic analysis in psychology. Qualitative Research in Psychology, 3, 77-101.

Buchan J. \& Seccombe I. (2011) A decisive decade: Mapping the future NHS workforce. London: Royal College of Nursing.

Bulechek G.M., Butcher H.K. \& Dochterman J.M. (2008) Nursing Intervention Classification (NIC) System. 5. Mosby; St Louis, MO.

Crotty M. (2005) The Foundations of Social Research. Sage, London.

Denzin N.K. \& Lincoln Y.S. (eds) (2000) Introduction: the discipline and practice of qualitative research. In Handbook of Qualitative Research, 2nd edn, Sage, London, pp. 1-30.

Department of Health (2013) The Cavendish Review: An independent review into Healthcare Assistants and Support Workers in the NHS and social care settings. London, HMSO.

Elias E. \& Murphy N. (2012) Home care of children and youth with complex health care needs and technology dependencies. Pediatrics, 129 (5), 996-1005. 
Emerson E. \& Baines S. (2010) Health Inequalities and People with Learning Disabilities in the $U K$. London: HMSO.

Gerrard B., Lambe L., \& Hogg J. (2010) Invasive procedures: minimising risks and maximising rights. Improving practice in the delivery of invasive procedures for people with profound and multiple learning disabilities. Dundee: PAMIS and White Top Research Unit, University of Dundee.

Glendinning S., Kirk, A. \& Guiffrida, D. (2001) Lawton Technology-dependent children in the community: definitions, numbers and costs. Child Care Health Development 27 (4), 321-334.

Hasenfeld, Y. (1985) "Citizens' encounters with welfare state bureaucracies", Social Service Review, 59 (4), 622-635.

Hasson F., McKenna H. \& Keeney S. (2013) Delegating and supervising unregistered professionals: The student nurse experience. Nurse Education Today, 33, 229-235.

Henderson, D.P. \& Knapp. J.F (2005) Report to the national consensus conference on family presence during paediatric cardiopulmonary resuscitation and procedures. Paediatric Emergency Care. 21, 787-791.

Hithersay R., Strydom A., Moulster, G. \& Buszewicz, M. (2014). Carer-led health interventions to monitor, promote and improve the health of adults with intellectual disabilities in the community: A systematic review. Research in Developmental Disabilities, 2014, 35, 887-907.

Kennedy A. \& Sawyers S. (2008) Transition from pediatric to adult services: are we getting it right? Current Opinion in Pediatrics, 20, 403-409.

MacKay D., G. Smith G., Dobbie R. \& Pell J. (2010) Gestational age at delivery and special educational need: Retrospective cohort study of 407, 503 schoolchildren. PLoS Med, 36 (6), 110 .

Matthews B. \& Ross, L. (2010) Research methods. A practical guide for social scientists. Pearson Longman: Essex.

Maulix P., Mascarenhas M., Mathers C., Dua T. \& Saxena S. (2011) Prevalence of intellectual disability: A meta-analysis of population-based studies. Research in Developmental Disabilities 32, 419-436.

METeOR 2005 Clinical Intervention. Available from:

http://meteor.aihw.gov.au/content/index.phtml/itemId/327220. Date of access: 19/11/2014/

Nankervis K., Rosewarne A. \& Vassos M. (2011) Why do families relinquish care? An investigation of the factors that lead to relinquishment into out-of-home respite care. Journal of Intellectual Disability Research, 55 (4), 422-433.

Nursing and Midwifery Council, 2010. Standards for Proficiency for Pre-Registration Nursing Education. London: Nursing \& Midwifery Council. 
Oeseburg B., Dijkstra G., Groothoff J., Reijneveld S. \& Jansen D. (2011) Prevalence of chronic health conditions in children with intellectual disability: A systematic literature review.

Intellectual and Developmental Disabilities, 49, 59-85.

Parahoo K. (1997) Nursing Research: Principles, Processes and Issues. Palgrave Macmillan, Basingstoke.

Royal College of Nursing (2006) Supervision, accountability and delegation of activities to support workers: A guide for registered practitioners and support workers. London: Royal College of Nursing

Royal College of Nursing (2008) Managing children with health care needs: Delegation of clinical procedures, training and accountability issues. London: Royal College of Nursing.

Royal College of Nursing (2012) Managing children with health care needs: Delegation of clinical procedures, training and accountability issues. London: Royal College of Nursing.

Ritchie J., Spencer L. \& O'Conner W. (2008), "Carrying out qualitative analysis," In J. Ritchie and J. Lewis, eds., Qualitative research practice. A guide for social science students and researchers. Sage: London. pp. 219-262.

Scottish Government (2013) The keys to life. Edinburgh: The Stationery Office.

Seltzer M., Floyd F., Song J., Greenberg J. \& Hong J. (2011) Midlife and aging parents of adults with intellectual and developmental disabilities: Impacts of lifelong parenting. American Journal on Intellectual and Developmental Disabilities, 116 (6), 479-499.

Standing T. \& Anthony M. (2008) Delegation: What it means to acute care nurses. Applied Nursing Research, 21, 8-14

Strauss, A. L. \& Corbin, J. (1990), Basics or qualitative research: grounded theory, procedures and techniques Sage: London.

Wark S., Hussain R. \& Edwards H. (2014) The training needs of staff supporting individuals ageing with intellectual disability. Journal of Applied Research in Intellectual Disabilities. DOI: $10.1111 /$ jar.12087

World Health Organisation (2011) World Report on Disability. Geneva: World Health organisation. 
Table 1: Specific elements required to enable ICI delivery

- A competency-based approach to delivering ICIs

- Agreed individual clinical protocols for ICI delivery

- Written individual goals for ICI delivery

- Audit cycles - regular updating and reassessing of competence

- Evaluation criteria of ICIs

- Statements of service and professional accountability

- Confidentiality of service user and families

- Care of the ICI equipment

- Medical device education

- Emergency management and risk assessment

(Adapted from: Royal College of Nursing, 2012: 5) 
Table 2: Groups involved in provision of care

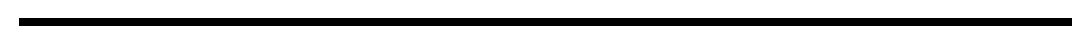

Groups involved in Care

Classroom staff/ Home teacher

Community Nurses/ community children's nurse

Dieticians

Family Friends

Holiday program staff

Occupational therapists

Paediatrician

Parents and other family members

Physiotherapists

School Nurses

Social Workers

Specialist Nurses e.g. Gastrostomy nurse, respiratory nurse

Support staff 
Figure 1: Thematic map of qualitative data analysis

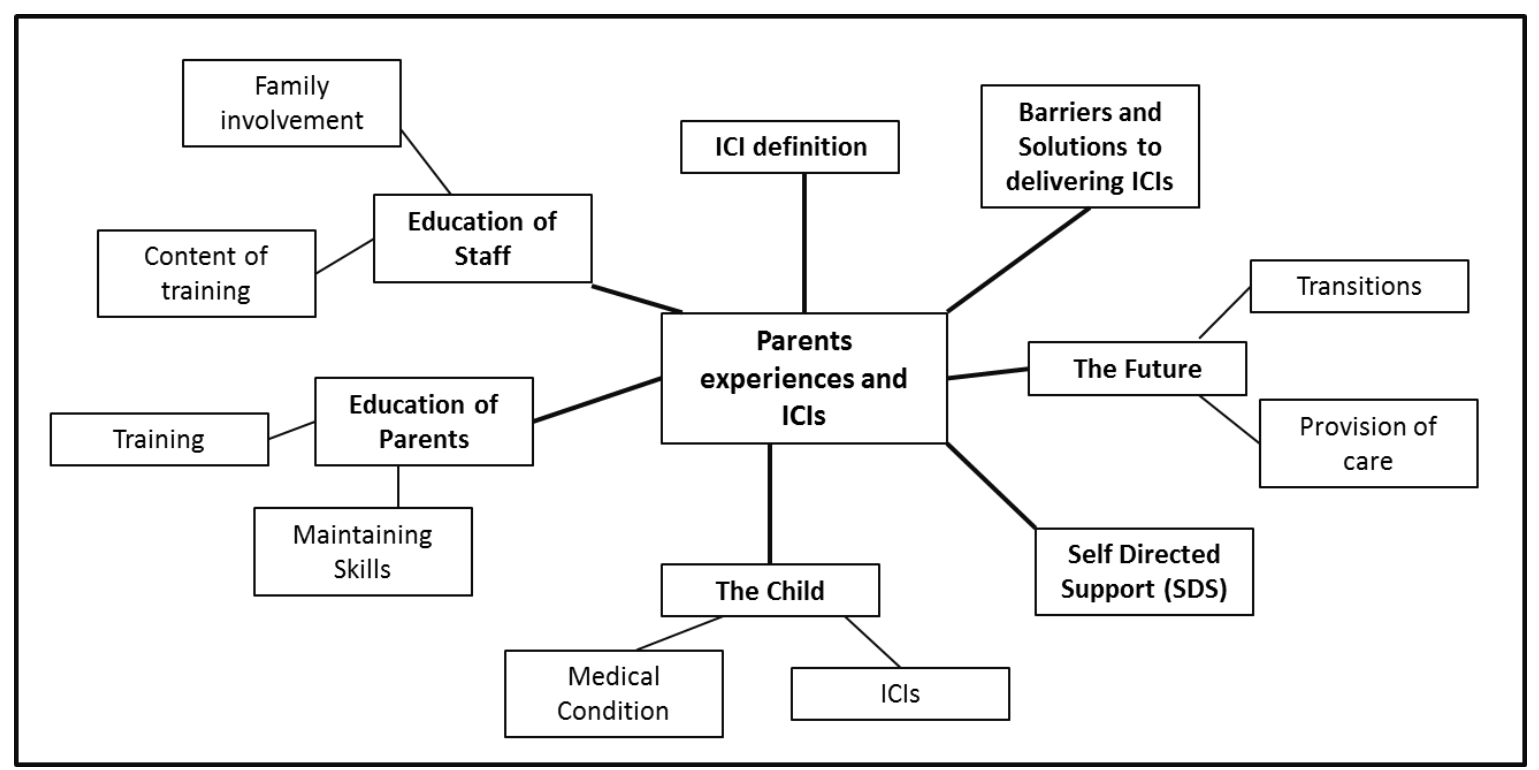

